\title{
Studies on $\mathrm{Bi}-\mathrm{Sr}-\mathrm{Ca}-\mathrm{Cu}-\mathrm{O}$ glasses and superconducting glass ceramics
}

\author{
R SINGH and E ZACHARIAS \\ School of Physics, University of Hyderabad, P.O. Central University, Hyderabad 500134 , \\ India
}

\begin{abstract}
Bi}-\mathrm{Sr}-\mathrm{Ca}-\mathrm{Cu}-\mathrm{O}$ glasses and glass ceramics of various compositions were synthesised. The glass transition temperature varies from 396 to $422^{\circ} \mathrm{C}$ depending on the glass composition. The bulk glass ceramics of $4334,4336,2223$ and 4246 compositions show superconductivity when the corresponding glass samples were heat-treated in air at $820^{\circ} \mathrm{C}$ for $3,9,12$ and $24 \mathrm{~h}$ respectively. X-ray diffraction studies show that the superconducting phase present in all these compositions is $\mathrm{Bi}_{2} \mathrm{Sr}_{2} \mathrm{Ca}_{1} \mathrm{Cu}_{2} \mathrm{O}_{x}$. The 4334 glass ceramic is almost a single-phase material with a preferred orientation such that the $c$ axis is normal to the sample surface. The 2223 glass ceramic has a higher $T_{c}$ (onset) than the other three compositions indicating the presence of high $T_{c}$ phase $(110 \mathrm{~K})$ also. ESR studies on the glass samples indicate the existence of $\mathrm{Cu}^{2+}$. The effect of heat treatment on ESR shows that the intensity of resonance decreases with increase in heat-treatment duration. This effect is more pronounced for the 4334 and 2223 compositions. The advantages of synthesizing superconducting materials by glass route are discussed in view of practical applications.
\end{abstract}

Keywords. Glass; glass ceramics; porosity.

\section{Introduction}

Several extensive studies have been reported on $\mathrm{Bi}-\mathrm{Sr}-\mathrm{Ca}-\mathrm{Cu}-\mathrm{O}$ oxides ever since the discovery of high temperature superconductivity in these materials. Recently the synthesis of $\mathrm{Bi}-\mathrm{Sr}-\mathrm{Ca}-\mathrm{Cu}-\mathrm{O}$ superconductors was reported by heat treatment of the amorphous glasses of this system (Hink et al 1988; Inoue et al 1988; Garzon et al 1988; Haixing and Mackenzie 1988; Singh and Zacharias 1989; Zacharias 1989). Since the composition of such glasses can be accurately controlled, it is possible that these metastable glasses could be devitrified by controlled heat treatment to give reproducibly crystallized superconductive materials. The crystallized material called the glass ceramic is pore-free and can be produced in various specific shapes as film, fibre, tape or wire. The synthesis of $\mathrm{Bi}-\mathrm{Sr}-\mathrm{Ca}-\mathrm{Cu}-\mathrm{O}$ superconducting materials by glass-route, is therefore, important in view of the practical applications of these materials. In this paper we present studies on $\mathrm{Bi}-\mathrm{Sr}-\mathrm{Ca}-\mathrm{Cu}-\mathrm{O}$ glasses and the corresponding glass ceramics.

\section{Experimental details}

\section{$2.1 \mathrm{Bi}-\mathrm{Sr}-\mathrm{Ca}-\mathrm{Cu}-\mathrm{O}$ glasses}

Glass samples of various compositions including $\mathrm{Bi}_{4} \mathrm{Sr}_{3} \mathrm{Ca}_{3} \mathrm{Cu}_{4} \mathrm{O}_{x}, \mathrm{Bi}_{4} \mathrm{Sr}_{3} \mathrm{Ca}_{3} \mathrm{Cu}_{6} \mathrm{O}_{x}$, $\mathrm{Bi}_{4} \mathrm{Sr}_{2} \mathrm{Ca}_{4} \mathrm{Cu}_{6} \mathrm{O}_{x}, \quad \mathrm{Bi}_{4} \mathrm{Sr}_{2} \mathrm{Ca}_{4} \mathrm{Cu}_{4} \mathrm{O}_{x}, \quad \mathrm{Bi}_{5} \mathrm{Sr}_{3} \mathrm{Ca}_{3} \mathrm{Cu}_{6} \mathrm{O}_{x}, \quad \mathrm{Bi}_{2} \mathrm{Sr}_{2} \mathrm{Ca}_{2} \mathrm{Cu}_{3} \mathrm{O}_{x}$ were synthesized. The powders of bismuth oxide, strontium carbonate, calcium carbonate and copper oxide were mixed in appropriate ratios in a mortar agate. The mixture was then melted at $1000^{\circ} \mathrm{C}$ for $2 \mathrm{~h}$ in air in alumina crucible. The transparent melt was quenched rapidly on a thick copper block and pressed by a copper plate. Dark red glass (about $1 \mathrm{~mm}$ thick) was obtained and used for various measurements. The detailed studies 
including differential scanning calorimetric studies and electrical conductivity vs temperature measurements were published elsewhere (Singh and Zacharias 1989). The electrical conduction in these glasses is characteristic of the small polaron-hopping semiconductors. The glass transition and crystallization temperatures and other physical parameters of these glasses are given in table 1.

\section{$2.2 \mathrm{Bi}-\mathrm{Sr}-\mathrm{Ca}-\mathrm{Cu}-\mathrm{O}$ glass ceramics}

The glass ceramics of various compositions were synthesized by heat treating the corresponding bulk glass samples in air. The glass samples were heat-treated at $820^{\circ} \mathrm{C}$

Table 1. Various physical parameters of the $\mathrm{Bi}-\mathrm{Sr}-\mathrm{Ca}-\mathrm{Cu}-\mathrm{O}$ glasses.

\begin{tabular}{lcccccc}
\hline Conductivity & $\begin{array}{c}\text { Activation } \\
\text { energy at } 300 \mathrm{~K}\end{array}$ & $\begin{array}{c}\text { Glass transition } \\
\text { temp. }\left(T_{g}\right)\left({ }^{\circ} \mathrm{C}\right)\end{array}$ & $\begin{array}{c}\text { Cryst. temp. } \\
T_{c}\left({ }^{\circ} \mathrm{C}\right)\end{array}$ & $\begin{array}{c}\text { Density glass } \\
\left(\mathrm{g} / \mathrm{cm}^{3}\right)\end{array}$ & $\begin{array}{c}\text { Density } \\
\text { (glass- } \\
\text { ceramics) } \\
\left(\mathrm{g} / \mathrm{cm}^{3}\right)\end{array}$ \\
\hline 4334 & $4.5 \times 10^{-7}$ & 0.39 & 396 & 456 & $5 \cdot 7$ & $6 \cdot 2$ \\
4336 & $1.6 \times 10^{-6}$ & 0.28 & 402 & 463 & 5.3 & 6.0 \\
4244 & $1.4 \times 10^{-8}$ & 0.44 & 422 & 467 & 5.1 & 5.5 \\
4246 & $1.6 \times 10^{-8}$ & 0.22 & 399 & 466 & 5.3 & 5.8 \\
5336 & $1.7 \times 10^{-8}$ & 0.23 & 418 & 460 & 5.9 & 6.2 \\
2223 & $5.9 \times 10^{-8}$ & 0.17 & 408 & 451 & 5.4 & 6.1 \\
\hline
\end{tabular}

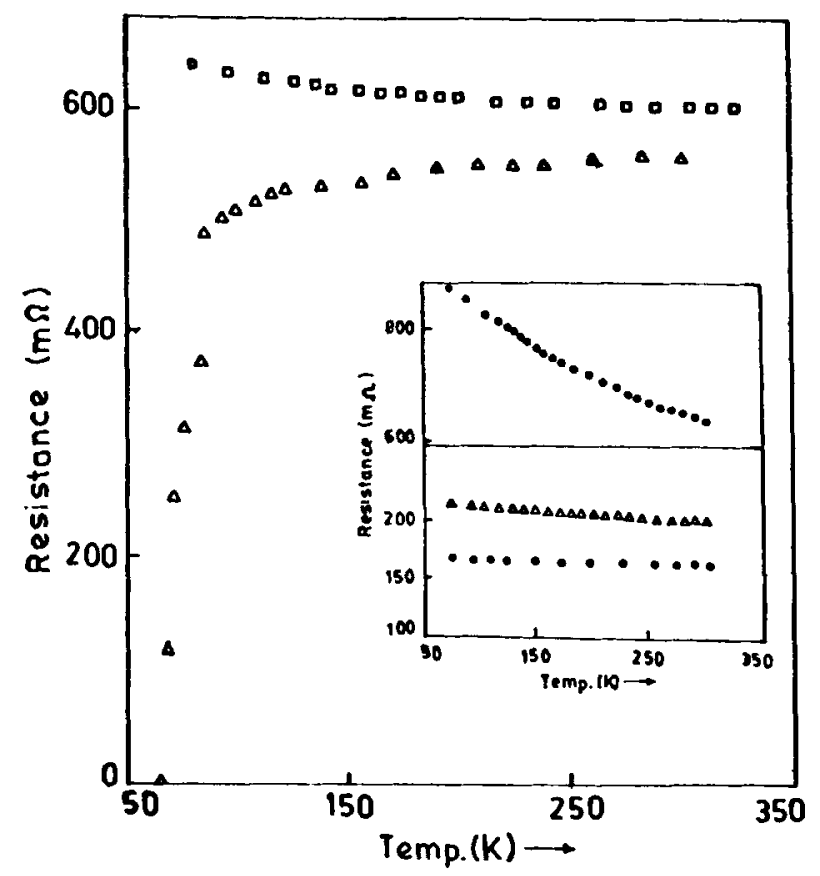

Figure 1. Resistance vs temperature for $\mathrm{Bi}_{4} \mathrm{Sr}_{2} \mathrm{Ca}_{4} \mathrm{Cu}_{6} \mathrm{O}_{x}$ glass ceramics heat-treated at $820^{\circ} \mathrm{C}$ for $(\square) 12 \mathrm{~h}(\triangle) 24 \mathrm{~h}$. Inset: $\mathrm{Bi}_{5} \mathrm{Sr}_{3} \mathrm{Ca}_{3} \mathrm{Cu}_{6} \mathrm{O}_{x}$ glass ceramic heat-treated at $820^{\circ} \mathrm{C}$ for (O) $12 \mathrm{~h}$ and $\mathrm{Bi}_{4} \mathrm{Sr}_{2} \mathrm{Ca}_{4} \mathrm{Cu}_{4} \mathrm{O}_{x}$ for $(\triangle) 12 \mathrm{~h},(\bigcirc) 24 \mathrm{~h}$. 
for the required duration which was restricted to a maximum of $24 \mathrm{~h}$. Resistivity was measured by the standard four-probe method with silver paste electrical contacts. The glass ceramics of 4244 and 5336 compositions show semiconduting behaviour even after $24 \mathrm{~h}$ of heat treatment while compositions 4334, 4336, 2223 and 4246 become superconductors with $T_{c}$ (onset) above liquid nitrogen temperature after heat treatment for $3,9,12$ and $24 \mathrm{~h}$ respectively. For all these compositions the $T_{c}$ (onset) and $T_{c}$ (zero) increases and the normal-state resistivity at a temperature decreases with increase in heat-treatment duration. The resistivity decreases linearly from room temperature until the $T_{c}$ (onset). The 2223 glass ceramic has higher $T_{c}$ (onset) and $T_{c}$ (zero) than samples of other compositions for the same heat-treatment duration. Figures 1,2 and 3 show the resistance versus temperature for glass ceramics heat-treated for various duration. Tarascon et al (1988a) reported that $T_{c}$ (zero) of the $\mathrm{Bi} \mathrm{Sr} \mathrm{Ca} \mathrm{Cu} \mathrm{O}$ system depends on annealing temperature. The closer the annealing temperature to the melting point, the higher the $T_{c}$ (zero). Since 2223 sample shows a higher $T_{c}$ (onset), the effect of still higher annealing temperature was studied for this composition. $T_{c}$ (zero) increased to $80 \mathrm{~K}$ when heat treatment at $840^{\circ} \mathrm{C}$ was carried out for $24 \mathrm{~h}$ for this composition. A comparison of $T_{c}$ (zero) for 4334 glass ceramic to that reported by Haixing et al (1988) shows that our sample has a $T_{c}$ (zero) almost $20 \mathrm{~K}$ higher than reported by them. This may be due to the higher melting and annealing

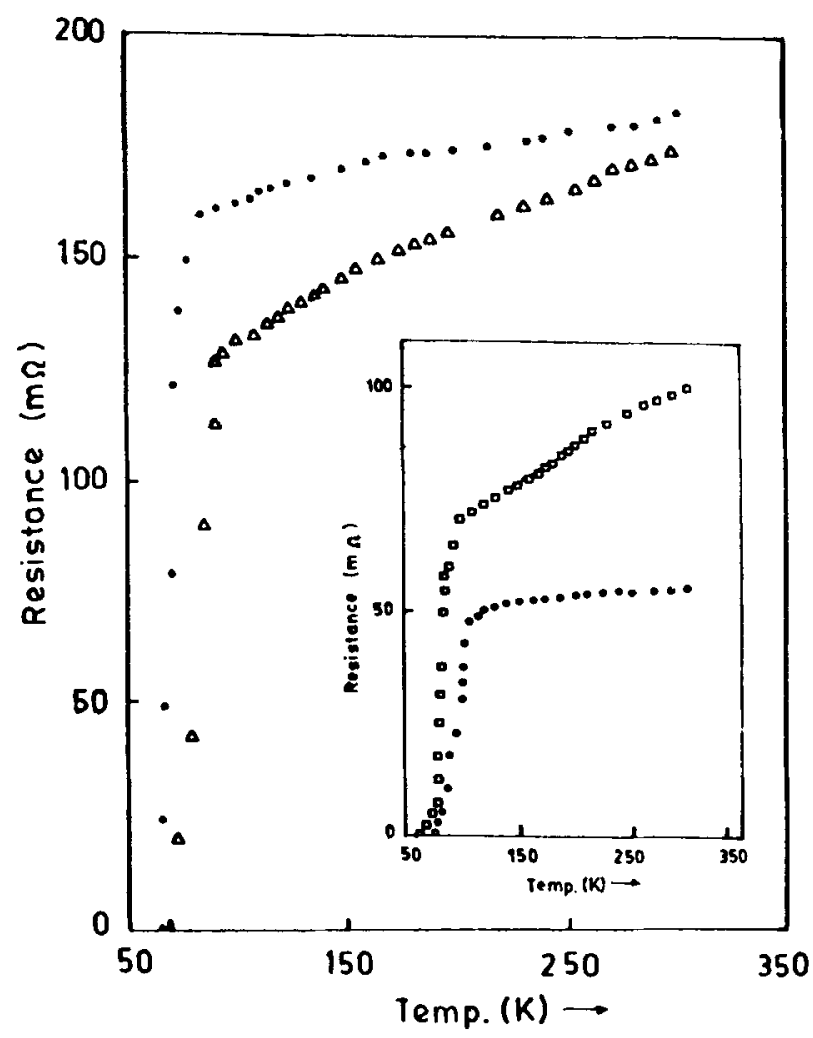

Figure 2. Resistance vs temperature for $\mathrm{Bi}_{4} \mathrm{Sr}_{3} \mathrm{Ca}_{3} \mathrm{Cu}_{4} \mathrm{O}_{x}$ glass ceramic heat-treated at $820^{\circ} \mathrm{C}$ for $(O) 3 \mathrm{~h}(\Delta) 12 \mathrm{~h}$. Inset: $\mathrm{Bi}_{2} \mathrm{Sr}_{2} \mathrm{Ca}_{2} \mathrm{Cu}_{3} \mathrm{O}_{x}$ glass ceramic heat-treated at $820^{\circ} \mathrm{C}$ for (口) $12 \mathrm{~h} \mathrm{(O)} 20 \mathrm{~h}$. 


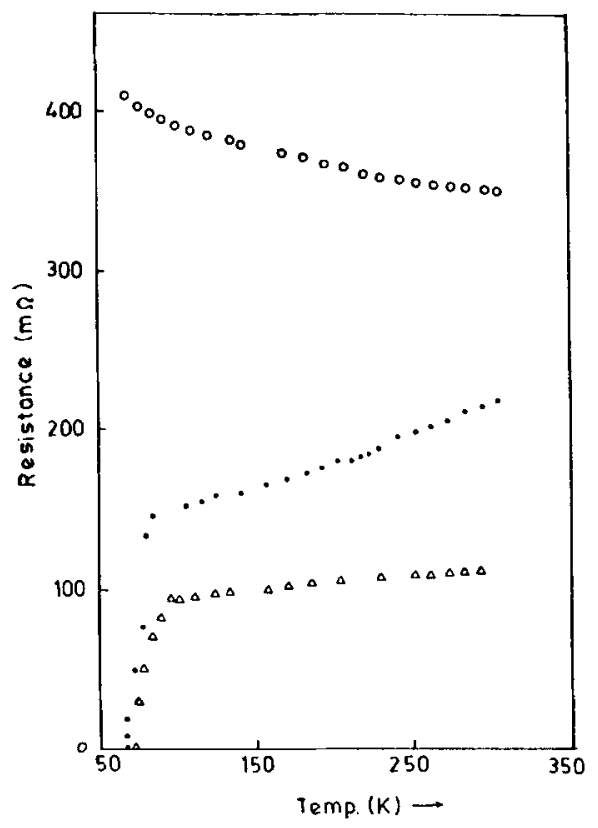

Figure 3. Resistance vs temperature for $\mathrm{Bi}_{4} \mathrm{Sr}_{3} \mathrm{Ca}_{3} \mathrm{Cu}_{6} \mathrm{O}_{x}$ heat-treated at $820^{\circ} \mathrm{C}$ for $(\mathrm{O}) 6 \mathrm{~h}$ (O) $12 \mathrm{~h}(\triangle) 24 \mathrm{~h}$.

temperatures used by us. It is quite likely that $T_{c}$ (zero) depends on the quenching rate also as the composition of the crystals and their general orientation are determined the moment when glass is formed by quenching the melt. $T_{c}$ (zero) is also likely to be enhanced as the annealing duration is increased for more than $24 \mathrm{~h}$. Further studies are in progress to optimize the composition, quenching rate and the heat treatment conditions in order to enchance $T_{c}$ (zero) of the $\mathrm{Bi}-\mathrm{Sr}-\mathrm{Ca}-\mathrm{Cu}-\mathrm{O}$ glass ceramics.

\section{$2.3 X$-ray diffraction studies}

Figure 4 shows the X-ray diffraction pattern of the bulk and powder (ground from the bulk) sample of 4334 composition. The pattern was indexed on the basis of studies reported by Tarascon et al (1988a) indicating the presence of superconducting $\mathrm{Bi}_{2} \mathrm{Sr}_{2} \mathrm{CaCu}_{2} \mathrm{O}_{x}$ phase with a tetragonal unit cell $(a=3.8 \AA, c=30.6 \AA)$. It can be noticed that peaks corresponding to [001], where $l$ is even, are enhanced considerably in the bulk XRD spectra as compared to that in the spectra of the powdered sample. These enhanced peaks arise from the atom planes perpendicular to $c$ axis. This shows that the sample has a preferred orientation with the $c$ axis normal to the sample surface. The enhancement of peaks corresponding to $[0,0,1]$ reflections is observed for other superconducting samples also but the enhancement is not as pronounced as in the case of the 4334 composition. For the XRD pattern of the sample compositions 4336, 4246 and 2223 (figure 5) most of the peaks can be ascribed to $\mathrm{Bi}_{2} \mathrm{Sr}_{2} \mathrm{CaCu}_{2} \mathrm{O}_{x}$ crystalline phase (low $T_{c} 85 \mathrm{~K}$ phase). The unassigned minor peaks for these compositions perhaps arise either due to unreacted $\mathrm{CuO}$ or some unidentified phase. Although the sample of 2223 composition has higher $T_{c}$ (onset) $[110 \mathrm{~K}]$ in comparison to other compositions, the XRD pattern is dominated by $\mathrm{Bi}_{2} \mathrm{Sr}_{2} \mathrm{CaCu}_{2} \mathrm{O}_{x}$ 


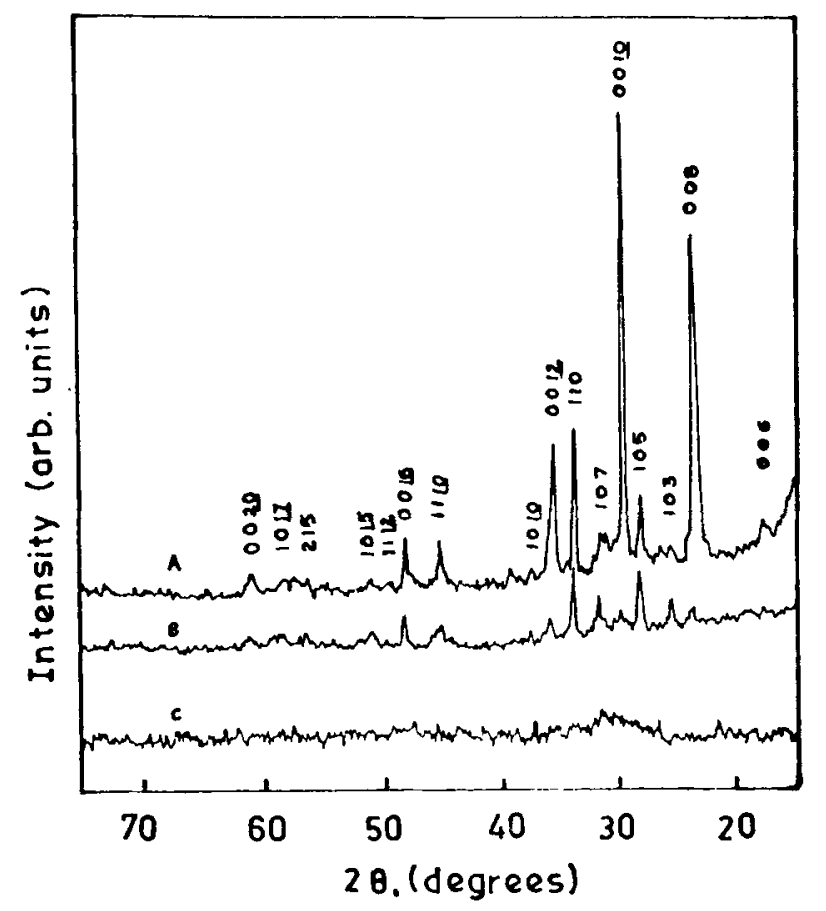

Figure 4. X-ray diffraction pattern for $\mathrm{Bi}_{4} \mathrm{Sr}_{3} \mathrm{Ca}_{3} \mathrm{Cu}_{4} \mathrm{O}_{x}$ glass ceramic (A) bulk (B) powdered glass ceramic (C) glass [Miller indices for each peak is assigned based on Tarascon et al 1988a].

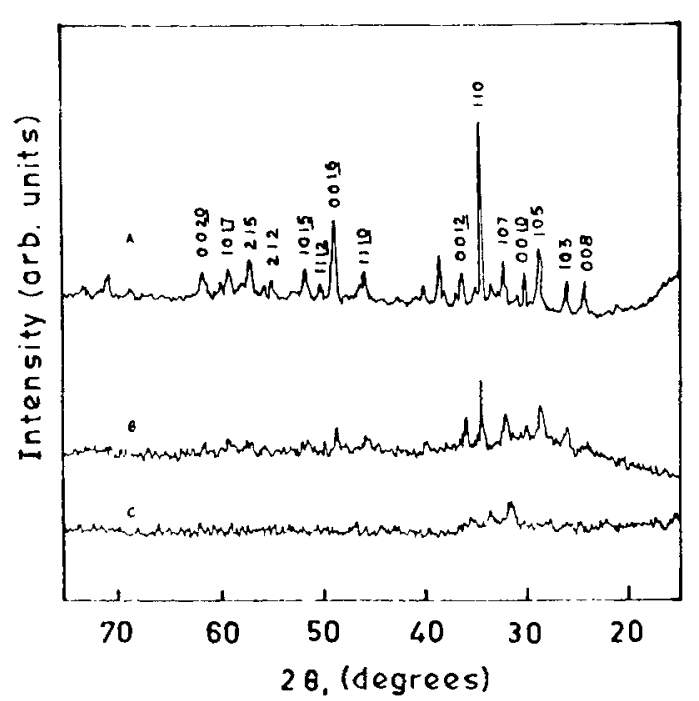

Figure 5. X-ray diffraction pattern for $\mathrm{Bi}_{2} \mathrm{Sr}_{2} \mathrm{Ca}_{2} \mathrm{Cu}_{3} \mathrm{O}_{x}(\mathrm{~A})$ glass ceramic bulk (B) powdered glass ceramic $(C)$ quenched sample. 
(low $T_{c}$ ) phase. This may be due to the fact that the presence of high $T_{c}$ phase $\mathrm{Bi}_{2} \mathrm{Sr}_{2} \mathrm{CaCu}_{3} \mathrm{O}_{x}$ even up to $20 \%$ is not evidenced by X-ray studies (Tarascon et al 1988a).

SEM studies on the bulk glass ceramic samples show plate-like crystals with a preferred orientation which is in agreement with XRD studies. SEM studies also showed that the glass ceramic was almost dense. The calculated density of the 4334 glass ceramic is $6.35 \mathrm{~g} / \mathrm{cm}^{2}$ (Haixing and Mackenzie 1988). The measured density of our sample of this composition is 6.20 . This means that the glass ceramic is about $98 \%$ dense. A comparison of the density of glass and glass ceramics indicates that a large shrinkage of glass takes place as a result of crystallization (table 1).

\subsection{ESR studies}

The room temperature ESR spectra of the glass samples consist of a broad resonance centred at $g \simeq 2 \cdot 3 \pm 0 \cdot 1$. In the case of 4244 and 4246 glass samples a very weak hyperfine structure was observed. These results indicate that the magnetic ion of copper exists in these glasses as $\mathrm{Cu}^{2+}$. The effect of heat treatment (heat treatment done in the same way as for obtaining superconducting glass ceramics) shows that the intensity of the ESR signal decreases with increase in heat-treatment duration with no change in $g$ and $\Delta H$ within experimental errors. This effect is more pronounced in the case of superconducting compositions especially 4334 and 2223 . Figure 6 shows the ESR spectra for 4334 and 2223 samples heat-treated for various durations.

The chemical analysis results on sintered $\mathrm{BiSrCaCuO}$ bulk samples (Tarascon et al 1988b) and XPS studies (Yeh et al 1989) on thin films of amorphous and superconducting $\mathrm{BiSrCaCuO}$ system show that the $\mathrm{Cu}^{2+}$ concentration remains unchanged as the oxide undergoes the insulator-superconductor transition through the high temperature anneal. The observed reduction in ESR signal intensity thus cannot be ascribed to the conversion of $\mathrm{Cu}^{2+}$ to another nonmagnetic valence state of copper. These results are either characteristic of insulator-metal transition or of rearrangement of $\mathrm{Cu}^{2+}$ spins such as antiferromagnetically-coupled $\mathrm{Cu}^{2+}-\mathrm{O}-\mathrm{Cu}^{2+}$ associates as a result of high temperature anneal. Detailed studies are in progress to understand the ESR results and their correlation with the superconducting properties of these glass ceramics.

\section{Conclusions}

The $\mathrm{BiSrCaCuO}$ glasses and glass ceramics of various compositions were synthesised. The glass ceramics of $4334,4336,4246$ and 2223 produced by crystallization of the corresponding glasses show superconductivity above liquid nitrogen temperature. The 4334 glass ceramic can be converted into superconductive material containing low $-T_{c}(85 \mathrm{~K})$ phases with preferred orientation relatively more easily than glass ceramics of other compositions. The 2223 glass ceramic shows the promise of becoming a superconductive material containing a high- $T_{\mathrm{c}}(110 \mathrm{~K})$ phase. ESR studies show that it is hard to observe ESR signal in good quality superconductive material.

The reasons for the low critical current density $J_{c}$ of high- $T_{c}$ superconducting ceramics are now well established viz (i) high porosity of the ceramics, (ii) random distribution of the crystals and (iii) the presence of impurity phases. For practical 


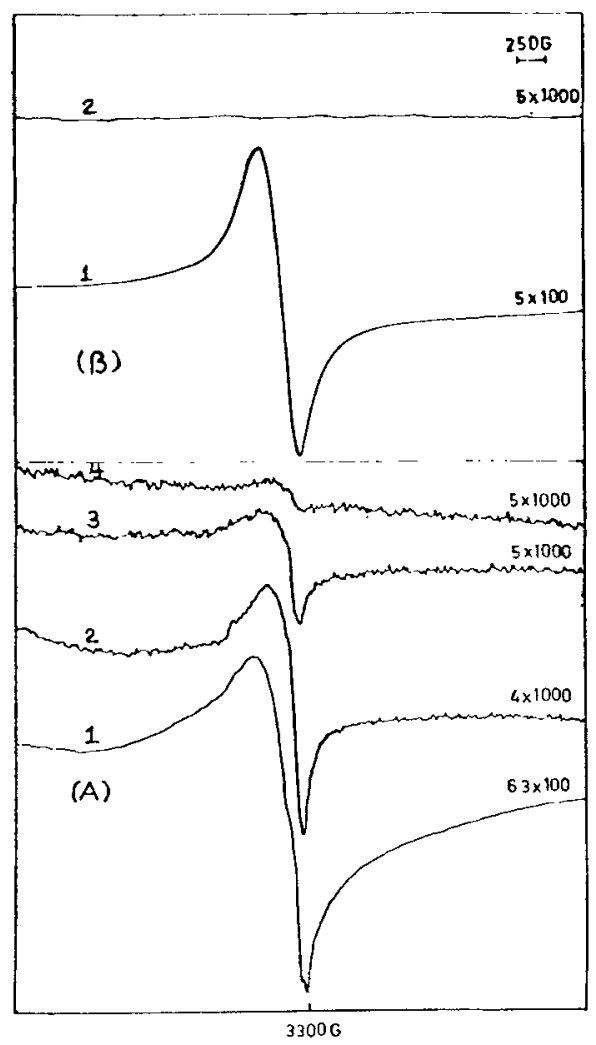

Figure 6. ESR spectra for (A) $\mathrm{Bi}_{4} \mathrm{Sr}_{3} \mathrm{Ca}_{3} \mathrm{Cu}_{4} \mathrm{O}_{x}(1)$ glass and heat-treated sample at $820 \mathrm{C}$ for (2) $3 \mathrm{~h} \mathrm{(3)} 6 \mathrm{~h}$ (4) $15 \mathrm{~h}$. (B) $\mathrm{Bi}_{2} \mathrm{Sr}_{2} \mathrm{Ca}_{2} \mathrm{Cu}_{3} \mathrm{O}_{x}$ (1) glass and heat-treated sample at $820 \mathrm{C}$ for (2) $12 \mathrm{~h}$ (The number on each spectra represents the gain of the spectrometer).

applications of the superconducting material in the form of ribbon, film or wire, it is necessary for the plate-like crystals to overlap with their $c$ axis normal to the surface, since superconductivity is poor parallel to the $c$ axis. The preferred orientation ( $c$ axis normal to sample surface) and the almost pore-free structure of the present $\mathrm{Bi}-\mathrm{Sr}-\mathrm{Ca}-\mathrm{Cu}-\mathrm{O}$ materials especially the material of 4334 composition, hold the possibility of improving $J_{c}$ which has practical applications for these superconducting materials.

Further work is being carried out to optimize the glass composition, atmosphere, temperature and other heat-treatment conditions so as to enhance $T_{c}$ (zero).

\section{Acknowledgments}

One of the authors (EZ) gratefully acknowledges financial support from the Department of Atomic Energy. This work was supported by the Department of Atomic Energy and the University Grants Commission. 


\section{References}

Garzon F H, Beery J G and Raistrick I D 1988 Appl. Phys. Lett. 53805

Haixing Z and Mackenzie J D 1988 Phys. Rev. B38 7166

Hink D G, Soderholm L, Capone II D W, Dabowski B, Mitchell A W and Shi D 1988 Appl. Phys. Lett. 53423 Inoue A, Kimura H, Matsuzaki K, Tsai A and Masumoto T 1988 Jpn J. Appl. Phys. 27 L941

Singh R and Zacharias E 1989 J. Phys. D22 (to appear)

Tarascon J M, Le Page Y, Barboux P, Bagley B G, Greene L H, Mckinnon W R, Hull G W, Giroud M and Hwang D M 1988a Phys. Rev. B37 9382

Tarascon J M, Mckinnon W R, Bardoux P, Hwang D M, Bagley B G, Greene L H, Hull G W, Le Page Y, Staffel N and Giroud M 1988b Phys. Rev. B38 8885

Yeh J J, Dicenzo S B, Hartford Jr E M, Hong M and Felder R J 1989 Appl. Phys. Lett. 54377

Zacharias E $1989 \mathrm{Bi}-\mathrm{Sr}-\mathrm{Ca}-\mathrm{Cu}-\mathrm{O}$ glasses and superconducting glass ceramics, M. Phil. Thesis, University of Hyderabad, Hyderabad, India 